\title{
La paz: \\ un sistema humanizador complejo
}

\section{Peace: a complex humanizing system}

\author{
Harold Armando Juajibioy Otero*
}

\section{Resumen}

El presente artículo planteó como problema de investigación la disputa, dispersión y disgregación de distintas nociones de paz a la hora de abordar la fundación y puesta en marcha del naciente proceso de construcción de paz en Colombia y, a posteriori, instó a desafiar esa disgregación e incomunicación desde la representación de una categoría alternativa capaz de integrar, poner en simbiosis e hibridación las perspectivas para ganar corpulencia.

Bajo un enfoque metodológico cualitativo de tipo exploratoriodescriptivo, se procuró buscar, reconocer, describir y ampliar los contenidos, fundamentos y perspectivas que pueden ser el contenido y el cuerpo amplio de la construcción de paz; reto perceptivo que exigió asociar los métodos complejo/sistémico para abrir un campo de discusión con el fin de re-imaginar una categoría alternativa: un sistema de paz complejo y conscientemente humanizador.

\footnotetext{
* Harold Armando Juajibioy Otero. Multiversidad Mundo Real Édgar Morín. Centro de Cooperación Regional para la Educación del Adulto en América Latina y el Caribe. Mocoa - Colombia. Correo: harold.juajibioy@gmail.com

Recibido el 04 de septiembre de 2019. Entregado el 30 de septiembre de 2019.
}

Medicina y Ética - Octubre-Diciembre 2019 - Vol. 30 - Núm. 4 
H. A. Juajibioy Otero

Como resultado se obtuvo una taxonomía tentativa de las posturas conceptuales actuales y antiguas, la descripción tanto de sus atributos, dimensiones y funciones, como de sus incomunicaciones, restricciones, limitaciones, a manera de un torbellino creativo de lo diverso que condujo a la posibilidad de toparse con una emergente concepción de paz capaz de integrar, poner en diálogo y relacionamiento algunos avances investigativos en materia del cultivo de la paz.

Palabras clave: nociones de paz, dimensiones, perspectivas, complejidad, sistema pacificador.

\section{Introducción}

La predominancia conceptual y de aplicación de unas nociones de paz sobre otras ha llevado al Estado, académicos, investigadores y sociedad en general a establecer formas inacabadas, inconclusas y fallidas de construcción. De ahí, la importancia de abordar el problema de su invención inconclusa y de sus limitaciones para superar el conflicto armado que se le antepone para, a posteriori, poder transitar de la dispersión de nociones al encuentro-distinción que propicie el nacimiento de una categoría tentativa capaz de establecer un diálogo y cooperación.

Este enfoque de trabajo investigativo cuenta ya con un avance significativo, representado en la invención y puesta en marcha de distintas categorías de concepción de paz, tales como: paz negativa y positiva (Galtung, 1985, p. 76), la paz como proceso (Lederach, 2007, p. 101), la paz compleja (Muñoz, 2005, p. 10), entre otras, que cobran relevancia frente al actual acuerdo de negociación entre el Estado y las FARC, el cual se innovó para poner fin al conflicto armado en Colombia.

A razón de lo anterior, el estudio se limita a realizar una revisión bibliográfica de textos producidos por investigadores para la paz, 
así como también de distintos estudiosos sobre el conflicto en Colombia, con el fin de encontrar los contenidos necesarios que soporten la tesis de trabajo sobre un terreno problemático, donde una concepción de paz unidimensional es insuficiente e ineficiente.

Bajo este enfoque, no se procura un trabajo empírico cualitativo de las realidades específicas, con hechos y características que permiten prever su impacto en la vida de los seres humanos; no obstante, hace uso de algunos hitos significativos que son referentes a visualizar, examinar y posicionar para darle consistencia a las argumentaciones que fundamentan la problemática.

De esta manera, el estudio se enfocó en el análisis e integración de corrientes de pensamiento sobre la paz, el entrelazamiento de contenidos heterogéneos, y la apertura de una escena donde las disimiles posibilidades logren intercomunicarse, cooperar y funcionar en conjunto; procurado concretar dos fines: primero, incubar una categoría abierta e inacabada de construcción de paz y, segundo, dejar como reflexión a académicos, gobernantes, investigadores y activistas sociales la urgente necesidad de evitar reducir y simplificar su constitución.

Como campo de interpretación se trabajó con base en la realidad conflictiva y problemática de Colombia, y teniendo en cuenta el actual tránsito de la guerra a la negociación y consolidación de acuerdos enfocados a instaurar la paz justa, democrática y con perspectiva territorial.

\section{Método}

La aplicación de una metodología cualitativa de tipo exploratoriadescriptiva se enfocó en reconocer distintas concepciones de paz y detallar algunas propiedades y características integradas entre estas corrientes conceptuales, para luego describir y fundamentar una categoría conceptual más amplia que contenga todos los elementos descritos. 
Para darle contenido y sustancia a esa categoría abarcativa de paz fue necesario usar cuatro principios reflexivos inherentes al pensamiento complejo y sistémico. Principios que, al funcionar en conjunto, concedieron la posibilidad de pensar y re-inventar la representación del contenido de la paz como un sistema de vida que humaniza.

El principio de lo múltiple facilitó la identificación de diversas teorías, perspectivas y sucesos que dan cuenta de la necesidad de una re-construcción de la idea paz desde su complejidad. El diálogo/distinción abrió el camino de análisis desde el reconocimiento de lo diverso. La relación heterogénea llevó al investigador a reconocer y observar el fenómeno en toda su amplitud y complejidad sistémica. Y, finalmente, el principio hologramático, sin descuidar las partes de un todo, entrelazó lo teórico y las experiencias que contribuyen al entendimiento del actual proceso de paz.

Para describir conceptos, perspectivas y categorías tentativas de comprensión se recurrió a información documental de investigadores que aportan a la fundamentación de la paz, y el seguimiento a escritos de análisis de la coyuntura actual de Colombia en materia de terminación definitiva del conflicto armado. La información recopilada se sistematizó en matrices de síntesis para reconocer categorías emergentes a partir de la relación de información bajo una lógica de búsqueda de una categoría alternativa de comprensión de la paz desde la complejidad.

Al ser un análisis preliminar de una categoría conceptual tentativa más que un muestreo poblacional, se recurrió a describir sucesos que impactan en la sociedad colombiana y sobre realidades regionales que marcan en contenido y sustancia a una u otra tendencia de construcción de paz.

Bajo esta lógica se construyó un análisis tentativo de las nuevas posibilidades de pensar y poner en marcha la construcción de paz en la sociedad colombiana. 


\section{Resultados}

\section{Diálogo con las concepciones de «paz»}

La innovación conceptual de la paz, al fundarse desde la división de concepciones y fundamentos heterogéneos, ha propiciado el estancamiento de su evolución como proceso e ideal humano. Por otra parte, su implementación bajo esa lógica de reducción, separación y simplificación, ha provocado un impacto limitado en la superación del conflicto armado en Colombia.

Es claro que la paz no puede instituirse con un contenido y significado unidimensional; de ahí el interés de fundamentar una categoría alternativa bajo el análisis del pensamiento complejo y sistémico. Un análisis que permita instalar en un mismo campo de observación, reflexión y diálogo sus concepciones históricas, dimensiones, maniobras, actores involucrados y, a la vez, posibles tentativas de sostenibilidad de cara a aportar al arduo proceso que se adelanta en el país.

Para alcanzar este desafío, es necesario hallar ideas de encuentro y relación entre el pensamiento complejo y el pensamiento sistémico.

Según Morín, el pensamiento complejo consiste en la habilidad humana de «reconectar lo que fue artificialmente separado. Su misión se fija en el adagio latino «sparsa colligo», y que implica «reconectar lo que está disperso» (Morín, 2014, p. 8).

Por otra parte, el pensamiento sistémico permite analizar el fenómeno como un todo constituido por partes heterogéneas en interacción, y que, por tanto, exige al investigador «ampliar la visión y tomar en cuenta todos los aspectos, y las interacciones entre las diferentes partes del problema» (Checkland, 1993, p. 19): es decir, lo convoca a asumir una postura de diálogo entre las «relaciones, dinámicas, y sinergia, de cada una de las piezas del rompecabezas para que encuadren perfectamente en un todo coherente» (Maldonado, 2009, p. 4). 
Teniendo en cuenta que lo complejo es «aquello que no puede resumirse en una palabra maestra, retrotraerse a una ley, o reducirse a una idea simple» (Morín, 1990, p. 21), la tentativa de definir la paz no puede someterse a una palabra unificada y concluida, principalmente porque sus concepciones franquean siempre por controversias, tensiones y disputas (de tipo intelectual, ideológico, social y cultural) para poder alcanzar finalmente una aceptación social.

Si analizamos las distintas concepciones implicadas en su fundamentación o instalación, podemos percatarnos de las tensiones y forcejeos generados entre estas; tensiones que surgen bien sea por sus mismos contenidos, fines, predominancia de una dimensión sobre la otra, desconocimiento de su constitución multidimensional, y en especial por el forcejeo entre precursores y opositores.

Bajo esta lógica, es muy necesario analizar primero las barreras que impiden el encuentro entre las nociones descritas, para avanzar en la edificación de un sistema conceptual renovado y abarcativo. Procurando, dentro de ese relacionamiento y diálogo, encontrar dimensiones ocultas, principios puentes de intercomunicación, y elementos emergentes que abren paso a una nueva categoría tentativa, abierta e inclusiva de aquello que está disperso conceptual y empíricamente.

En Colombia, una tendencia generalizada de construcción de paz se asocia a la pretensión de relacionarle o de exigirle el único fin de la seguridad a secas; no seguridad humana (en su amplitud), sino más bien una concepción de seguridad unidimensional basada en el fortalecimiento de la fuerza pública para el sometimiento o eliminación del enemigo y, por consiguiente, de la guerra. Una perspectiva altamente peligrosa debido a sus impactos negativos en la vida humana.

Según Valencia, analizando las estadísticas del Registro Único de Víctimas (RUV), en el periodo de gobierno de Pastrana y el auge de la seguridad democrática del gobierno de Uribe, se produjeron los índices más altos de hechos víctimizantes: 
En el gobierno de Andrés Pastrana Arango se produjeron 2.453.628 víctimas y en los dos mandatos de Álvaro Uribe Vélez 3.374.270. Son 12 años que van del 7 agosto de 1998 al 7 de agosto de 2010. Suman 5.827.898 víctimas, es decir, el 70,13 por ciento del total de las víctimas existentes en el conflicto en Colombia (Valencia, 2016).

Esta aparente seguridad militarista, bajo lógicas de índices de efectividad perversos, provocó en su tiempo los delitos más atroces e inhumanos, precisamente porque su concepción no afronta de manera directa los orígenes de los conflictos, se resiste al cambio de imaginario del enemigo, y define como único camino de estabilidad el incremento de la fuerza armada para mantener el orden establecido. Tortosa califica esta postura como «el camino fácil de producir y convivir con la violencia bajo la lógica de pensar en leyes, policía y ejército» (Tortosa, 2001, p. 11), y a la vez el camino falseado, miope y cómodo de bienestar de unos pocos, a costa de la inseguridad de otros.

En igual dirección, la noción minimalista, especializada, en reducir la violencia a partir de la generación de condiciones para el diálogo entre las partes, tiene otro enfoque y propósito, busca llegar a un acuerdo definitivo para terminar con el conflicto armado. Esta perspectiva es conocida y aplicada a nivel global, y Colombia tiene ya sus referentes (negociación con el M19, EPL, PRT, y el Quintín Lame), logrando «pactar la terminación del conflicto armado y sentando las bases para la desmovilización, todo esto en el marco de ceses unilaterales al fuego previo a las negociaciones» (Romero , 2013, p. 6).

Como proceso, integra acciones de diálogos, pactos, y acuerdos para la dejación de armas, desminado humanitario, reincorporación de los actores armados y demás acciones de superación del conflicto. Tiene la tendencia a fijar en un espacio específico donde ocurre la confrontación, y el tiempo de intervención se limita al momento de la superación de la guerra o de la violencia generalizada. Sin embargo, en su operar no confronta otros sistemas de funcionamien- 
to social (estructuras políticas, dinámicas económicas, dominios territoriales, funcionamiento del Estado, etc.) que provocaron el origen de las controversias, de los conflictos y la guerra.

En el otro extremo, la noción maximalista relaciona todas las variables implicadas en la construcción de paz, analiza las causas estructurales que provocaron el conflicto y a la vez las posibilidades de cambio a partir del mismo, fijando su objetivo no sólo en mitigar la guerra, sino también en prevenir nuevos brotes de conflicto y violencia. Según Rettberg, la concepción maximalista «buscaría generar las bases para superar las causas «estructurales» de los conflictos, como la pobreza, la inequidad y la exclusión» (Rettberg, 2002, p. 3), y tiene la visión de «generar las condiciones propicias para fomentar el desarrollo económico, político y social del país en cuestión» (Rettberg, 2002, p. 2).

Su enfoque exige un proceso de largo plazo que atraviesa la reducción de la guerra, la superación de la misma y la concretización de condiciones positivas que transformen sus orígenes; por consiguiente, no se rige por un solo pacto, sino por múltiples pactos que abarcan otros sistemas de vida social, política, económica y territorial. Su intención de abarcar un mayor número de factores que explican el conflicto sobrepasa el análisis de los actores en confrontación y se adentra a conocer las causas estructurales que conllevaron al surgimiento de la violencia, para poner sobre la mesa las posibilidades y alternativas no recorridas. Al tener un enfoque abarcativo, puede ser demasiado idealista y poco aplicable en un contexto donde las condiciones políticas, económicas y jurídicas están permeadas o cerradas por estructuras rígidas.

Las Naciones Unidas nos dejan el legado de la paz cosmopolita, entendiendo la paz como un derecho a ser protegido y promovido a nivel global.

En el año 1992 el Secretario General de las Naciones Unidas, Boutros Boutros-Ghali lanzó el «Programa para la paz», dejando en claro cuatro modalidades de trabajo para prevenir y afrontar los conflictos armados en el mundo: 
Primero, la diplomacia preventiva, entendida como los esfuerzos de la comunidad internacional para evitar que el conflicto armado llegue a producirse; segundo, cuando el conflicto es inevitable, se busca encontrar los orígenes de su surgimiento para resolverlo (peacemaking); tercero, desarrollo de negociaciones y acuerdos para mantener la paz (peacekeeping), y cuarto, la construcción de paz (peacebuilding) enfocada a reconstruir lazos sociales, instituciones y sistemas de vida afectados por la guerra (Ghali, 1992, p. 6).

Su contribución tiene dos aspectos valiosos: primero, establecer la paz como derecho universal, y segundo, instalar un proceso de prevención, promoción y protección de la misma, bajo la cooperación internacional para todo el ámbito global.

Frente a la anterior propuesta, ya en el siglo XVIII Kant también instó a las naciones a poner en marcha la noción de paz perpetua, como derecho que se debe situar universalmente entre los Estados y bajo principios morales comunes de acción de éstos y sus poblaciones. Su perspectiva exhorta al rescate de la constitución republicana basada en la libertad de todos los ciudadanos, dependencia de todos ante la ley e igualdad entre las poblaciones (Kant, 1998, p. 15). En el mismo sentido de las Naciones Unidas, Kant establece que es un imperativo la existencia de un organismo internacional que procure avanzar en la prevención e instalación de la paz entre las naciones, al igual que re-imaginar los Estados para promover libertades humanas y resolver las desigualdades que generan tensiones y conflictos entre las poblaciones, y de éstas con el Estado. Para Kant no es suficiente un acuerdo entre partes jerárquicas, o un pacto entre los actores en conflicto, siendo más bien un conjunto de pactos entre pueblos que contribuya a la construcción de paz como un deber político, moral y ético.

En la experiencia de Colombia, es posible toparse con otras nociones emergentes de construcción de paz, que tienen que ver con la paz en relación a: el desarrollo, la construcción de territorio, la 
reinvención del Estado, el fortalecimiento de la democracia, la justicia transicional, entre otras. La paz en relación a, permite reajustar o reinventar las nociones de desarrollo (desarrollo rural, desarrollo justo) de justicia (como acceso a la verdad y reparación de las víctimas, la discusión de las formas de judicialización y amnistía para los actores armados, y el debate de la justicia social) en democracia (re-imaginar las formas de representación política y de participación ciudadana) y en construcción de territorio (reivindica las potencialidades de sociedades campesinas, afros e indígenas como afectados por el conflicto y precursores de nuevas dinámicas de pacificación).

Las perspectivas embrionarias de construcción de paz en relación $a$ un fin concreto puede contribuir en la dotación de contenido a la paz maximalista, cosmopolita, y de construcción de paz (peacebuilding), en la medida que responden a resolver inequidades, fomentar la participación ciudadana, ampliar los partidos políticos, re-imaginar a las regiones la relación con el Estado, también resuelven otras violencias, reconstruyen relaciones rotas entre sectores poblacionales y promueven la reconciliación desde varias perspectivas. Sin embargo, para la experiencia colombiana, sus contenidos y puestas en marcha carecen de fuerza y practicidad. Un ejemplo de ello es la euforia sobre la exigencia que implica la construcción de paz territorial, que ya es criticada por su incipiente aplicabilidad de acuerdo con el contexto actual:

La paz territorial estará concentrada en zonas del territorio caracterizadas por grandes brechas en la provisión de bienes y servicios públicos, pero también por la débil presencia del Estado (Vargas, 2017, p. 3).

Precisamente, hablar de paz territorial, al enfatizar en lo «territorial», evidencia una grave falla estructural que Colombia ha sufrido durante toda su existencia con algunas excepciones históricas cortas y mal implementadas: un centralismo agudo y torpe que ha ocasionado muchos de nuestros problemas, entre éstos varios conflictos violentos (Gonzales, 2016, p. 2). 
Las dos argumentaciones en forma de crítica auguran un riesgo estructural en la consolidación de la paz territorial, debido a la débil estructura de un Estado frente a los retos de trasformación de regiones excluidas históricamente. Por ahora, todas las ideas de paz en relación $a$, son intentos prematuros que pueden ser corroídos con facilidad por las nuevas coyunturas políticas, o diluidos por la carencia de financiamientos en el largo plazo y absorbidos por las dinámicas imperantes.

Finalmente, una última perspectiva tiene que ver con la autobiografía de la construcción de paz. Como aquella comprensión y a la vez capacidad humana de reconocer que todos podemos hacer las paces desde el punto de vista interpersonal (pactando la no violencia), social (reconociendo al otro como legítimo otro en la convivencia) e institucional (fortaleciendo la democracia y la gobernanza local) (Martínez, 2008, p. 2). Como un llamado a «integrar la dimensión personal en el problema de la paz» (Tortosa, 2001, p. 23) con base en las facultades y experiencias de la gente; es decir, asumiendo «un empoderamiento pacificador» capaz de adherir prácticas, acciones y capacidades pacifistas para trasformar la realidad (Sandoval, 2015, p. 88).

El empoderamiento pacificador exige un llamado al reconocimiento emblemático de individuos y líderes, organizaciones, movimientos políticos, investigadores, grupos poblacionales y actores institucionales; esto, como enaltecimiento a su labor de inspirar a una sociedad en la construcción de una nueva vía de relacionamiento humano. Esta perspectiva exige «retomar los referentes humanos de no violencia, de pacificación interna y en la promoción de actitudes no-violentas hacia el exterior humano y no humano (Sandoval, 2015, p. 87).

Puede ser que estas nociones (desde la seguridad humana, paz minimalista, maximalista, con relación a y autobiográfica) no sean aún las suficientes para seguir cimentando la necesidad de una evolución humana pacifista, pero sí son básicas para seguir ahondando en esa concepción compleja de paz. 
Para la parte siguiente, se procura resolver la relación de las distintas concepciones a partir de los siguientes interrogantes: ¿cuáles son las dimensiones, componentes y sustancias valiosas que aportan estas concepciones? ¿cómo se pueden religar esas dimensiones y componentes en una concepción que les integre sin aislamientos? ¿qué nueva estructura puede surgir de esa integración que contribuya a una concepción más amplia de paz? ¿cómo puede funcionar esa concepción de paz multidimensional? y si esa nueva concepción tentativa ¿tiene la posibilidad de instalarse en Colombia a partir de los avances obtenidos en el actual acuerdo de paz entre el Estado y los actores en confrontación?

\section{Las paces: simbiosis e integración multidimensional}

En el aporte anterior nos percatamos de los esfuerzos por encontrar una concepción de paz viable; en ese mismo recorrido fueron apareciendo dimensiones entre una y otra concepción, por lo que en adelante se buscará respuesta a: ¿cuáles son las dimensiones que pueden estar contenidas en las distintas concepciones? y ¿cómo pueden encontrarse en relación y contribución mutua?, esto con el propósito de encontrar puentes de comunicación y relacionamiento.

La paz no puede ser pensada sin el análisis del pasado e interpelación del presente, sin la puesta en marcha de la dimensión histórica, que permite auscultar las razones y orígenes de la perpetuación de la guerra y a la vez las apuestas para trascender su prolongación. A manera de pregunta, es fundamental analizar los múltiples orígenes del conflicto, pasando por el debate del surgimiento de los victimarios, las víctimas, la omisión del Estado, las opulencias excluyentes, el monopolio del poder, las pobrezas e indignidades humanas, pero también integrando en el análisis, las razones del escepticismo social y el bajo involucramiento de la gente en los caminos de construcción de paz. 
Hacer el ejercicio de preguntas y respuestas intercomunicadas como reflexión, nos permiten activar la facultad de ver de forma hologramática las dimensiones que contiene el tejido histórico de la realidad, lo que implica «reintroducir el fenómeno a explicar en su contexto, para reconocer la parte y el todo, distinguir sin separar, encontrar simbiosis, complementariedades y combinaciones entre todo lo que esta interactuando» (De Almeida, 2008:21), evitando sesgarse ante lo que es complejo, y sobredimensionar una problemática en desmedro de otras.

Por tanto, la dimensión histórica facilita reconocer dos caminos en disputa y relacionamiento, el camino de los orígenes del conflicto versus el camino de reconocimiento de posibilidades de cultivo de paz; la historia es la fuente de transición curativa de los relatos de la violencia hacia los relatos capaces de soportar la edificación de la paz positiva, justa y digna para todos.

Por el mismo camino, de frenar las confrontaciones, aparece la dimensión médica de tratar los sintomas, de procurar la cura; es decir de aquello que menciona la historiadora Diana Uribe, «Parar la guerra, dejar de matarnos y salvar vidas» (Uribe, 2016). Cura que es buena, pero no suficiente, porque el enfermo puede volver a recaer en sus andanzas nocivas, o aún peor, saber que el contexto actual en el que vivimos es el productor continuo de perpetradores de distintas formas de violencia.

Esto nos advierte que parar la guerra no es suficiente si las mega estructuras político-militares y económicas de ilegalidad continúan. Estamos en mora de desmantelar toda la estructura que sustenta el conflicto armado y en especial de aprender a prevenir su repetición; esto, a través del reconocimiento y potenciación de aquellas cosas que los seres humanos hacemos bien, sin el uso de la violencia. Reivindicando esos momentos en que somos capaces de resolver los conflictos por la vía del diálogo, el acuerdo, la ley, la moral y la instalación de pactos pacíficos.

Desde otra arista, también aparece la preocupación por los responsables de la pacificación, aquella dimensión política que exige 
capacidades humanas para asumir los retos de la paz. Dimensión que insta el involucramiento democrático de todos los actores que erigen sus esfuerzos desde el ámbito público, privado, institucional y social. Su funcionalidad debe garantizar pactos entre los actores directos del conflicto, sectores amplios de movimientos políticos, círculos de pensamiento, víctimas y victimarios, pactos que amplíen el holograma de resultados y desmantelen formas de poder y violencia en los que están sumergidos comunidades, barrios, ciudades y la nación.

Si miramos desde la actuación política actual de los gobernantes en Colombia, el presidente Santos juega un papel relevante. Ha creado un paraguas basado en la coalición de partidos políticos que facilita los acuerdos; involucra sectores de la sociedad civil como activistas y promotores de la pedagogía social; invita a las Naciones Unidas a ser garantes de lo pactado; integra un amplio respaldo de académicos, e incluso involucra a los medios de comunicación como crítica y apoyo al proceso; abre el debate de la paz desde diversos frentes. En ese sentido, los actores políticos no sólo son los que imaginan la paz, sino también los que encuentran vacíos en su implementación.

En relación con la dimensión anterior, surge la pregunta de ¿para quién la paz?, evocando la dimensión social, aquella que revela el rostro humano del daño, los afectados por el conflicto, pero también los sujetos activos capaces de involucrarse en un proceso de reconstrucción humana.

En ese entramado de daños, afectaciones, sufrimientos, exclusiones y desigualdades surge continuamente la discusión de los derechos humanos. La necesidad de ahondar sobre por qué es tan deshumanizante la guerra, en qué afecta la dignidad, integridad, libertad e igualdad de los seres humanos. Postura moral universal que exige contar lo nocivo que ocurrió, y develar su impacto nefasto en la vida humana, con el fin de poner sobre la mesa pública la decadencia de unos mínimos de convivencia y de respeto a los derechos de los otros. 
En este ámbito, la paz se piensa y posiciona como un derecho cosmopolita inaplazable, con todo lo que su contenido e instalación implica: el acceso a la verdad, el respeto a la vida, la terminación con los tratos crueles e inhumanos, la culminación definitiva de la guerra, la resolución pacífica de conflictos y, en especial, la generación de condiciones para que la población pueda disfrutar de un trato justo e integral. Por consiguiente, la paz como derecho humano fundamental no sólo procura la declinación del conflicto armado, sino también la construcción de una cultura en la que se potencie todo aquello que nos hace más humanos.

Otro aspecto supremamente relevante tiene que ver con la continuidad del debate de la dimensión espacio-tiempo: ¿dónde debe ocurrir la paz?, ¿cuánto tiempo necesita para consolidarse? Las nociones de paz se han caracterizado por usar el enfoque linterna, donde alumbra el espacio, allí, de inmediato recurrimos a analizar y aplicar las medidas. Este acto afanoso reduce, delimita y divide los espacios como si no estuvieran intercomunicados; por consiguiente, es necesario superar esa lógica por una nueva mirada que pueda ver las relaciones y tensiones de un lugar a otro, y avanzar en esa relación hacia la pacificación duradera.

Está bien que la curación de la enfermedad se priorice en los lugares más afectados por la violencia, los territorios excluidos por el desarrollo, como, por ejemplo, el Municipio de Tumaco-Nariño, afectado por una economía ilegal hegemónica (coca), con una alta tasa de homicidios (70 por cada 100.000 mil habitantes); índices de pobreza aguda, y donde la disputa territorial se retoma por otros actores armados (Semana, 2017, p. 34); sin embargo, también es válido el argumento sobre una paz como derecho integrador, basado en la igualdad, justicia, libertad y trato justo, más allá de los espacios en confrontación, en una geografía nacional del derecho.

Es necesario que las ciudades dejen de crecer a espaldas de los territorios rurales, intentando que su relación sea re-imaginada en reciprocidad, y basada en la transferencia de todo campo de conocimiento, oportunidades, formas de desarrollo, modos de buen 
vivir, por consiguiente, de distribución equitativa de bienestar. Tiempos y espacios no deben disociarse en un proceso de paz, en especial, porque son construcciones sociales que se caracterizan por ser plurales y altamente contribuyentes en la producción de experiencias de paz como resistencia a la guerra, búsqueda de verdad, perdón, reconciliación.

$\mathrm{Al}$ seguir escudriñando las partes del cuerpo visible e invisible de la paz, es posible que nos topemos siempre con los retos para el Estado, un llamado a la reinvención de este ente. ${ }^{2}$ La reinvención de toda su estructura de funcionamiento. No sólo para garantizar los pactos necesarios frente al cese definitivo de las confrontaciones, sino también con relación a su propia forma de operar. Procurando que éste cuente con condiciones y capacidades para resolver las demandas sociales que exige la construcción de paz, y a la vez el desarrollo, la justicia, la relación entre ciudades y territorios, la alternatividad a lo político, el reinventar la democracia, y tener un rol más activo en la protección y promoción de los derechos humanos. Realmente requiere consolidarse en un Estado social de derecho, con mirada e intervención multidimensional ante realidades complejas.

En ese camino del hacer estatal, es importante también poner en marcha la dimensión económica con todos sus contenidos implícitos. Teniendo en cuenta que los recursos financieros son necesarios para instalar la paz, y deben ser utilizados con eficiencia, tanto para frenar la guerra como para superar la pobreza, favorecer el acceso a derechos, modernizar el campo, integrar a las regiones, superar las economías ilegales, y avanzar hacia el desarrollo justo, el buen vivir y el mejoramiento de la calidad de vida.

Otro elemento relevante en la construcción de la paz tiene que ver con la valoración ética de lo que hacemos: ese sentido filosófico del respeto a la vida, a la dignidad humana, y de resistencia a los sucesos degradantes e inhumanos. Volver a integrar en nuestras vidas la dimensión ética que nos constituye, y nos implica con deber y obligación en el debate de la paz. 
El sacerdote católico Roux menciona que «en medio de este desbarajuste humano somos una sociedad encerrada en el simplismo. Convencida de que el problema no es con nosotros, que todo lo ha causado un enemigo perverso y minoritario que actúa contra los buenos» (Roux, 2009, p. 1). Hemos perdido y dejado de ejercitar el deber moral. De este modo, transferimos la responsabilidad de resolver el problema al Estado y si éste llega a fallar, estamos listos a criticar su débil capacidad resolutiva. Para resolver esto es necesario que todos asumamos el reto de ubicarnos y actuar en los caminos experienciales de la convivencia, solidaridad, cooperación y concordia.

En la interacción de los anteriores aspectos, también urge comprender las repulsiones y uniones que se van generando. Reconocer su dimensión relacional. Así como el cuerpo necesita de la inhalación de oxígeno presente en el contorno, la dimensión relacional siempre está presente en la interacción multidimensional. Una dimensión que no está contenida al interior de cada una de las anteriores, sino que aparece precisamente a partir de sus encuentros y que permite avistar otros elementos de análisis. Por ejemplo, el esfuerzo del Estado produce un efecto menor en la búsqueda de la paz, si no se asocia de manera sinérgica con el esfuerzo de la academia, actores políticos, expertos en análisis jurídicos y de justicia, con la sociedad civil, los sectores económicos y los actores internacionales.

Igualmente, la sobreabundancia de recursos para la paz no tiene validez y eficacia sin la claridad y firmeza de los excombatientes en su decisión de renunciar a la guerra, la trasparencia de las autoridades territoriales en el uso de los recursos para la paz y el esfuerzo constante de la sociedad por superar las situaciones de ilegalidad y de uso de distintas formas de violencia.

Siempre la relación conjunta de múltiples actores con fines comunes de pacificación integra policapacidades y a la vez provoca polirresultados en simultaneidad. 
Finalmente, como la paz está en marcha, siempre estará pasando por umbrales de equilibrios y vuelta a turbulencias, precisamente por las distintas problemáticas que aborda.

Esta dimensión problemática no está excluida, siempre aparece en forma de controversia para reivindicar fundamentos, necesidades y demandas no integradas; surge en un momento de poca claridad e incertidumbre que exige creatividad para establecer nuevos entendimientos, alternativas y pactos. Es una dimensión de alerta para la actuación positiva frente a lo que no fue concebido, resolver un problema no discutido e integrar algo o alguien excluido; por tanto, la construcción de la paz no aparta las controversias, disputas, vacíos, turbulencias y desequilibrios, sino más bien trabaja con todo ello, con el fin de llegar a nuevas comprensiones.

Según Magendzo, el problematizar la realidad permite confrontar ideas, incrementar las desavenencias y desacuerdos (Magendzo \& Pevéz, 2015, p. 75), pero también dar apertura a nuevas ideas, posturas y novedades que pueden reforzar el proceso de construcción, en especial, porque este proceso hace parte de la discusión sociopolítica en la que hay que reflexionar, disertar, acordar y plantear posibilidades para llevar a cabo lo importante. Contribuye a la imaginación creativa y creadora de nuevas ideas jurídicas, políticas, educativas, culturales y sociales, capaces de hacer mutar una realidad negativa a partir de intentos razonables y plausibles.

En este viaje por el cuerpo de la paz, las dos últimas dimensiones son esenciales para comprender a las otras, ya que sin excepción alguna están presentes, bien sea como interacción, alcance de sinergias o como tensiones, desajustes y reajustes. Su no delimitación y evasión, a posteriori hace que aparezcan sorpresivas. De ahí que la gran dificultad de los actores de la paz radica en la imposibilidad de pensar los procesos en relación, sinergia, y comunicabilidad.

Es posible que en este recorrido de encuentro con las dimensiones heterogéneas del cuerpo de la paz aún no estén descritas todas 
en su gran mayoría, pero con las detalladas hasta ahora, podríamos decir que son las suficientes para soportar la necesidad de superar las nociones restringidas y funcionamientos aislados, a partir de la puesta en escena de una noción alternativa.

\section{Búsqueda de un sistema complejo de pacificación}

Hasta este momento nos hemos percatado de cuatro cosas: primero, la existencia de nociones de paz separadas, incomunicadas y en disputa entre sí; segundo, alcances limitados o parciales a razón de definiciones restringidas, dimensiones funcionando de manera separada y con resultados parciales; tercero, distancias y controversias sostenidas por las diferentes posturas argumentativas de los actores que las construyen; y cuarto, encuentro con posibilidades de diálogo y relación entre distintas acepciones a partir de sus componentes, mismas que permiten avizorar y argumentar la creación de una categoría tentativa que abre posibles escenarios de simbiosis conceptual.

De ahí la urgencia de encontrar una categoría más conciliadora, dialógica, abarcativa e implicativa de las nociones que han funcionado de manera separada. Una categoría que posibilite el diálogo entre éstas y sus actores bajo el reconocimiento de su multidimensionalidad potencial, la reunión fuera de sus límites en distinción y potenciación de sus dimensiones, caracterización de sus interacciones, tensiones y disputas, y con posibilidad de inventar una asociación de contenidos, que dé como resultado una unidad amplia: un sistema complejo de pacificación. Esto, procurando entender lo complejo como aquello que viaja más allá de lo que se pretendía dado por hecho, conceptuado, especializado, enfocado y puesto en marcha de manera aislada. De aquello que perpetúa la selección de una concepción bajo la repulsión de otras, que privilegia a ciertas dimensiones en olvido más que de otras, presta atención a unos actores en exclusión de otros, privilegia un espacio a diferencia de otros, etcétera. 
Resultado que va surgiendo del análisis del fenómeno de la paz como un suceso complejo y basado en sistemas evolutivos, en especial porque convoca a ligar, asociar y reunir bajo la distinción de nociones diversas, campos de conocimiento, dimensiones heterogéneas, interacciones, tensiones, y controversias en un mismo campo de análisis problematizador, y a la vez, que convoca a la curiosidad colectiva de re-imaginar la interacción de lo múltiple en forma de autoorganización, funcionalidad y evolución como un todo organizado y en autoproducción continua.

Es necesario reflexionar sobre lo complejo, como un «tejido (complexus: que está urdido en conjunto), compuesto de constituyentes heterogéneos inseparablemente asociados, y que, por tanto, presenta la paradoja de lo uno y lo múltiple» (Morín, 1990, p. 32); es decir, bajo la advertencia de Weaver citado por Rodríguez, de que la complejidad está organizada desde la «intervención de un número amplio de factores o variables interrelacionados que conforman un todo orgánico» (Rodríguez \& Aguirre, 2011, p. 6). Siendo complejo aquello que no está separado, sino que procura la interrelación y la conjunción heterogénea para llegar a constituirse como un fenómeno sistémico. Bajo esta premisa, la paz compleja puede llegar a ser aceptada como aquel proceso que une múltiples contenidos, conceptuaciones y significados, y que se caracteriza por conjugar múltiples componentes, operar simultáneamente en distintas direcciones y provocar impactos en el mismo sentido.

En complemento a lo anterior, un sistema complejo es «una representación de un recorte de una realidad, conceptualizado como una totalidad organizada, en la cual los elementos no son «separables»y, por tanto, no pueden ser estudiados aisladamente (García, 2006 , p. 21), y cuyo movimiento tiene como principios de funcionalidad: «una disposición de sus elementos por niveles de organización con dinámicas propias, pero interactuantes entre sí; y una evolución que no procede por desarrollos continuos sino por reorganizaciones sucesivas (García, 2006, p. 80). 
Dicho esto, la paz también reúne las condiciones para ser analizada y conceptualizada como un proceso sistémicamente complejo. Requiriendo tener en cuenta el tejido y diálogo de sus múltiples concepciones e intentos de aplicación, la interacción dialógica de sus dimensiones heterogéneas, la posibilidad de describir tentativamente una forma de funcionalidad autoorganizada desde sus interacciones sin exclusión de las tensiones, y de poder suponer su posible evolución en procesos continuos de consolidación.

Por consiguiente, para poder instalar esa categoría de sistema complejo de pacificación, no es suficiente con reconocer sus múltiples significados y dimensiones, lo que se trató en los anteriores apartados, sino que también exige posicionar aquellos principios dinámicos que le constituyen como sistema capaz de alcanzar funcionalidad y autorreproducción. Esos principios dinámicos son los siguientes:

El principio de lo uno y lo múltiple. La construcción de paz no puede ser conceptuada y dotada de significado desde una sola perspectiva; requiere reunir y ligar las distintas perspectivas. Su operar no puede regirse por la funcionalidad exclusiva de una dimensión en exclusión o falta de atención de las otras.

La misma dimensión política de la paz tiene su tejido complejo de actores. La dimensión política de la paz es incompleta sin la motivación y conciencia activa de la dimensión social; de ahí que los pactos no son suficientes entre el Estado y los actores armados, sino también pactos entre el Estado y la sociedad, entre actores políticos, económicos, culturales y de movimientos sociales. Es urgente en Colombia poder seguir dotando de sustancia a las dimensiones de la paz desde una postura de intercomunicación, interacción y puesta en marcha de manera simultánea; sólo así se provocarán poliefectos o polirresultados simultáneos. Lo uno y lo múltiple es constitutivo de un proceso de paz, e implica no separar o aislar lo que comienza a tejerse en conjunto, lo que aparece alternativo, e incluso lo que genera tensión en ese proceso de reconstrucción humana no violenta. El principio de lo uno y lo múltiple como actos humanos y acontecimientos autoproducidos, deben ser 
reconocidos y potenciados sin restricción en la búsqueda continua de formas de concordia.

Por otra parte, lo uno y lo múltiple exige un tejido desde la multiplicidad de nociones y dimensiones, de contenidos conceptuales, de fuerzas y capacidades de actores involucrados, de formas de Estado como espejo de respuesta a necesidades sociales, económicas, culturales y territoriales, de búsqueda de equilibrios entre espacios en construcción antro-posocial, recociendo a los sujetos de derechos desde varios enfoques y basado en la reconciliación, el perdón sustentado en la verdad, la ejercitación de los derechos humanos, retoma de la ética de la vida (reverencia a la vida misma y búsqueda de la dignidad de todos).

Esta noción amerita investigadores transdiciplinarios, ciudadanos y activistas capaces de abrir escenarios alternativos de encuentro entre saberes locales, regionales, nacionales e internacionales; actores políticos des-sujetados de patrones conservadores de gobernar y hacer política, activación de fuerzas colectivas desde las víctimas para reconstruir tejido social, comunidad y retoma de ciudadanía y, en especial, formas de reincorporación de los actores armados con soporte en la inserción activa en la vida social, económica, política y cultural desde lo local, región o de país.

Sin el uso de este principio de tejer lo múltiple a la hora de engrasar los dispositivos del operar de la paz, seguiremos expuestos a los azares de información falsa, a los radicalismos, a las oposiciones infundadas y, en especial, a ser parte de recorridos humanos que vuelven a exponernos a la violencia y la guerra. Pondré al respecto sólo un caso de percepciones no relacionales.

Actualmente generamos un balance entre el trato diferencial que tiene el Estado con los desmovilizados en comparación a los ciudadanos y educadores, y suponemos que hay un trato desleal ante los que se esfuerzan por cumplir con el orden democrático. Sin embargo, llevamos a la sombra el doble impacto del primer trato temporal. El primero, que una vez reincorporados los actores armados, muchas poblaciones recuperan su tranquilidad respecto a 
su libertad y seguridad; y segundo, la posibilidad de abrir condiciones para la recuperación y regreso de esos seres humanos desajustados al orden democrático y pacífico del país.

En ese viaje de lo uno y lo múltiple siempre debe estar presente el principio de la distinción. No podemos reconocer lo múltiple, si no hacemos el esfuerzo de distinguir los contenidos, elementos y características de aquello que es único, y sin distinguir aquello que surge como nuevo y alternativo de la interacción de lo múltiple.

El principio de la distinción es clave a la hora de implicar aquello que funciona disperso en la búsqueda de un proceso de pacificación, primero, porque permite reconocer lo que está constituido de manera heterogénea; segundo, encontrar contenidos claves de cada dimensión implicada; tercero, posibilita delimitar los efectos de esa interacción de lo múltiple; cuarto, trasciende las divisiones y funcionamientos aislados; por tanto, abre espacios de funcionamiento sinérgico, y quinto, nos permite contemplar sus impactos simultáneos y diversos. Distinguir los actores involucrados en la construcción de paz nos permite potenciar sus diversas formas de actuación y re-imaginar su implicación continua con los otros actores que van en la misma dirección.

Distinguir las formas de justicia en un proceso de paz nos permite trascender la restringida justicia sancionatoria y carcelaria, hacia la justicia de rehabilitación, de reparación, de equidad y trato justo y dignificante. Distinguir los impactos normalizados de la guerra frente a los nacientes impactos positivos de un escenario de negociación, pueden ayudarnos a crear referentes de nuevos caminos de resolución de problemas sin el uso de la violencia.

Los dos principios anteriores no pueden ser posibles sin el principio dialógico, que abre el espacio de encuentro, reunión, distinción y reconocimiento de nociones, perspectivas y dimensiones; es el principio dialógico el que propicia el relacionamiento, interacción y asociación hacia fines fundamentalmente humanizadores.

Si procuramos encontrar elementos comunicantes y complementarios entre nociones y dimensiones, y las colocamos en un 
escenario de trabajo conjunto, es posible que esa nueva unidad compleja de paz sea más efectiva en el propósito que persigue. Este principio posibilita que los fines de búsqueda de paz desde la concepción de seguridad, o desde las perspectivas minimalista, maximalista, cosmopolita y autobiográfica puedan ligarse y ponerse en marcha de manera diversa para ser más eficientes en la terminación de las guerras, resolver los conflictos de forma no violenta, recomponer los daños, integrar ampliamente a los actores, subsanar los factores estructurales que marginan y producen desigualdades, y a la vez relacionar el esfuerzo pacificador con otras nociones que hacen parte del sistema de vida humano.

Contribuye a que las dimensiones descritas puedan asociarse en un escenario nuevo y tentativo de autoorganización, el cual maximiza sus polipotencias en asociación con otras que vienen de otros campos de funcionamiento $y$, a la vez, provocar polipotencias emergentes que no existían en la maniobra aislada de cada una de ellas. Permite a los precursores de una u otra perspectiva abrir debates capaces de religar lo que está desunido, de crear escenarios de reflexión y trabajo conjunto, de trasformar sus percepciones y posturas, de hacer mutar sus estancamientos de ideas, y de re-imaginar nuevas categorías más razonables en el reto de construir paz. Por tanto, contribuyen a tener un mayor impacto en la trasformación de la realidad problemática.

En la predisposición al diálogo con lo múltiple, es posible que tengamos que estar alerta a los principios inevitables de equilibrio y desequilibrio, principios que surgen con consistencia cuando integramos nociones, dimensiones heterogéneas, formas de funcionamiento y actores en un proceso de pacificación compleja.

En el diálogo para llegar a la asociación de nociones divergentes, es inevitable pasar por la detección y reconocimiento de puntos de desacuerdo, tensiones, controversias, pero también de las posibles formas de conjunción, no sólo para crear una categoría alternativa, sino para poner en marcha su innovación. 
El equilibrio y desequilibrio como principios de constitución de paz posibilitan valorar lo programado y alcanzado, al igual que los nuevos retos que se requieren para afrontar las problemáticas que no se esperaban abordar.

La construcción de paz siempre estará convocando nuevas tensiones, resistencias y exigencias de los involucrados; por lo tanto, estas manifestaciones deben formar parte de su propia constitución e instalación. Esto ya sucedió en el proceso que se adelanta en Colombia, cuando el Estado establecía como única perspectiva de paz desde un enfoque minimalista, donde se privilegiaba como central la reincorporación de los actores armados, sobre la exclusión de otras. Pero esto se tropezó con los actores locales (bajo asesoría y activismos de la academia, los investigadores, las ONG) posicionando la necesidad de pactar acuerdos frente a la paz en relación a el desarrollo, al género, el acceso a derechos, reconstrucción de territorio, reparación eficiente de las víctimas y justicia social basada en la superación de la pobreza.

Dos casos son ejemplares desde las exigencias sociales para integrar propuestas a los acuerdos en La Habana: primero, incidencia de organizaciones de mujeres ante la mesa de negociación, que dio como resultado:

La inclusión de manera sistemática de la perspectiva de género en todos los seis puntos de la Agenda de negociación. En términos generales, este Acuerdo reconoce a las mujeres como sujetas de derecho y actoras políticas, quienes vivieron de manera diferencial el conflicto armado interno, prestando particular atención a su rol en la fase de implementación (Gómez, 2017, p. 14).

Segundo, las demandas de los movimientos campesinos instaron al Gobierno a abrir el debate de la reforma agraria integral como salida sostenible a la erradicación de los cultivos ilícitos, por tanto:

Las negociaciones en la Mesa Única del Gobierno y la Cumbre Agraria son piezas fundamentales en la reelaboración de estrategias de desarrollo integral que deben responder a los problemas de fa- 
milias, zonas y regiones que han estado involucradas en la economía de cultivos declarados ilícitos (González, 2015, p. 7).

De esta manera, la tensión y desequilibrio entre lo acordado y lo no previsto, abrió un nuevo ramal del contenido de paz y exigió otras formas de implementación. Es por esto que, al integrar nociones y dimensiones en el campo de la aplicación, se puede precaver a priori los efectos e impactos, pero también asombrarse de los impactos espontáneos, emergentes y alternativos no contemplados, pero asertivamente contribuyentes.

La mirada de equilibrio y desequilibrio nos permite observar a Colombia como el laboratorio alternativo de construcción de paz; principalmente debido a que tiene procesos espejo, adoptados de otras experiencias del mundo; empero, también experimenta su propia producción de salida definitiva de la guerra con un actor armado, integrando distintos enfoques y campos de acción.

Estos principios no evitan lo preestablecido, determinado, lineal y estable de la construcción de paz, sino más bien le integran a un campo de funcionamiento mayor donde lo previsible e imprevisible está apareciendo de manera simultánea. Un campo donde se privilegia tanto lo preestablecido o programado, como lo que aparece potencialmente espontáneo, emergente y novedoso. Un campo donde no se excluye, más bien se integra lo que aparece como resultado de todo un proceso autoorganizado. Es así que en Colombia no estaba prevista la movilización de jóvenes después de la caída del plebiscito procurando blindar el proceso de paz, la activación de masa crítica intelectual, de movimientos por la paz y de víctimas desde lo regional solicitando salvaguardar los alcances pactados para terminar la confrontación armada.

Ante la confianza desmedida del Estado de asegurar lo pactado por la vía democrática, poca atención se le tenía a la necesidad de anticipar la pedagogía para la paz; ahora es un proceso que se instala desde varios frentes. Las resistencias y tropiezos de los actores armados igualmente, no estaban previstos en la búsqueda de un acuerdo, pero bajo la premisa de negociar aún dentro de la guerra, 
se fue creando un escenario definitivo para su terminación como actor armado ilegal.

De esta manera, sumergiéndonos en los principios que unen complejidad y sistemas, estamos llegando al punto de equiparar la edificación de la paz como un proceso sistemático de autoorganización.

Según Foerster, citado por Morín, un «sistema auto-organizador es un sistema que debe trabajar, construir y reconstruir su autonomía y que, por lo tanto, dilapida energía» (Morín, 1994, p. 69). Esta premisa desde la perspectiva humana de la paz nos convoca a ser provocadores de su autoorganización como parte de nuestras vidas. Reconocer al ser humano como el autoproductor del sistema que lo autoproduce: la construcción de paz.

Por tanto, el principio de autoorganización exige esencialmente el involucramiento potencial de conocimientos, experiencias e inventivas de los actores en su máxima amplitud. Siendo los seres humanos los que van creando las nociones, contenidos y dimensiones, asociaciones y relaciones, formas de trabajo para el diálogo, alternativas de solución a las crisis, y especialmente experiencias y acontecimientos que transformas las realidades nocivas hacia realidades más pacíficas.

Para Moriello el principio de auto-organización «es la propiedad que tienen algunos sistemas de poder generar orden a partir del caos» (Moriello, 2016, p. 3), y ello se puede detectar y caracterizar como avance en los distintos procesos de construcción de paz en Colombia, mismos que siempre han procurado abrir alternativas dentro de las continuas crisis de violencia y confrontación armada. Esos referentes de intento de proveer orden dentro del caos pueden encontrarse en pactos exitosos con actores armados (con el M19), reincorporación de paramilitares, apertura de nuevos partidos políticos como contrapoderes ante los tradicionalistas, medidas de reparación a las víctimas, disminución significativa de las muertes violentas, involucramiento más decidido del Estado en las regiones, ampliación de la masa crítica en búsqueda de experiencias 
humanizantes, involucramiento de la academia, investigadores y medios de comunicación en el posicionamiento de conocimientos y experiencias que nutren el reto de transitar hacia un reencuentro más dignificante.

En esa vía de alcanzar proceso autoorganizado de paz, desde la autoría de los seres humanos, requiere que todos cultivemos un principio complementario: el principio bologramático, que permite observar de manera continua en «el menor punto de la imagen del holograma el contenido de casi la totalidad de la información del objeto representado» (Morín, 1990, p. 111). Un holograma social de mentes creativas que se conectan para analizar y reconocer los retos de la paz y las barreras que impiden su alcance, sin evitar aquellas contradicciones que enriquecen el debate.

Comenzar a aprender, contemplando con cautela el todo en la parte, en cada una de esas actuaciones microsociales continuas, y ver la parte como contribuyente del todo, en esos resultados que nos compenetran. Una actitud mental nueva que puede funcionar como herramienta de análisis para los investigadores, académicos y agentes que mueven los procesos de paz. Contribuir al Estado a abrir su campo de intervención hacia exigencias sociales que no sólo remedian los síntomas de la guerra, sino también los síntomas de la exclusión y desigualdad social. Inducir a las organizaciones, colectivos y sociedad en general a reconocer y tomar conciencias de rutas necesarias para salir definitivamente de la guerra y la violencia generalizada.

En síntesis, el observar la relación de las partes en el todo y viceversa, permite recuperar una aptitud humana de conectar y no disgregar, y de retomar la responsabilidad de ser parte de la edificación de nuevas relaciones, interacciones, y consensos.

Finalmente, llegamos al último principio, al más esencial, el principio autobiográfico: sabiendo que la paz requiere de la propia transformación humana, que sólo puede surgir de la reflexión y actuación de las personas que persiguen ese fin fundamental de 
relacionamiento pacífico, digno, justo, equilibrado y razonable para todos y todas.

Es un camino lleno de retos para tejer bajo la pregunta ¿qué aspiración de futuro tenemos a partir de la trasformación del presente? Por consiguiente, no hay noción ni dimensión que no sea puesta en marcha, principios que doten de contenidos a un sistema humanizador en la búsqueda de autoorganización y autoperpetuación, donde el ser humano como colectivo no esté implicado. Así que la paz siempre ha estado en el radio de reflexión y actuación humana; lo importante es no perder de vista ese potencial que está en cada uno de nosotros y en la actuación de la sociedad en su conjunto.

En ese sentido, el sistema complejo de pacificación no puede ser una teoría que soporta una noción significante, no puede ser unidimensional, reducido a unos pocos actores o dejado en manos de expertos, sino por el contrario, un recorrido continuo de la sociedad y de sus autoridades en procura de trasformar todas las causas de la producción de violencia y confrontación y, a la vez, potenciador de todas las ideas, nociones, estrategias, campos de acción, de actores, experiencias, acontecimientos, impactos y resultados que viajan por el camino de la instauración de sistemas de vida no violentos, humanizantes, equitativos, justos y potenciadores de lo humano.

El sistema complejo de pacificación sólo puede ser alcanzado bajo el reconocimiento de todas las posibles dimensiones, interacciones y principios de funcionamiento que le vayan dotando de una estructura, una autoproducción y prolongación en el tiempo.

El sistema complejo de pacificación sólo puede ser erigido por una amplia y continúa innovación de seres humanos participando en ámbitos de trabajo que viajen más allá de lo planeado y preestablecido.

La paz es un llamado a la creatividad continua de los seres humanos que hacen parte de una sociedad. 


\section{Discusión}

En el presente estudio se encontró que la concepción de paz en su evolución conceptual y de funcionamiento se ha ido fundamentando desde perspectivas separadas, simplificadas y reducidas en contenido, y que, por tanto, su impacto en la superación de los conflictos y violencias generalizadas ha sido reducido y poco efectivo.

La predominancia de una concepción aplicada en una determinada época provocó el desmedro de las otras concepciones, como ocurrió con el intento de llegar a la paz por medio de la seguridad armada, época en la que se generaron mayores índices de vulneraciones de derechos humanos y poco simplificó la confrontación armada.

Bajo el análisis de un enfoque sistémico y complejo se dejó en claro que la dispersión y baja comunicación de concepciones y prácticas para pacificar las relaciones humanas, ocurre por la ausencia de diálogo entre campos de conocimiento a la hora de abrir el debate teórico; la predominancia de unas dimensiones sobre el ocultamiento de otras, la aplicación de alternativas separadas para resolver conflictos, y la disgregación de los actores que les susten$\tan y$ ponen en marcha.

Para contrarrestar esta situación se planteó fundamentar un sistema de pacificación complejo, constituido por la relación contributiva de concepciones, intercomunicación de dimensiones heterogéneas y el desarrollo de acciones simultáneas para la trasformación de la realidad conflictiva y avanzar en la mejora de dinámicas económicas, sociales, culturales y territoriales.

Esto, con la intención de instituir dinámicas continuas y progresivas de nuevos funcionamientos del Estado, de reconstrucción de la vida social y económica de la sociedad, respeto y promoción de los derechos humanos, re-imaginación de la democracia, formas disímiles de resolución pacífica de conflictos, potenciación de alternativas para el desarrollo, del buen vivir y del trato justo y dignificante de la sociedad. 
En ese sentido, se enfatiza en la necesidad de consolidar la paz más allá de periodo de gobierno, de negociación restringida con actores en conflicto, y de una determinada época, para forjar un proceso de cultivo humano continuo y en evolución; posibilidad que exige poner en marcha la creatividad humana frente a la reinvención de sistemas de vida, teorías, concepciones y perspectivas de trabajo. Esto debe ser revelador en los seres humanos a la hora de adquirir el valor y fuerza para conducirse por este camino creativo que se revela de forma no violenta contra todo tipo de violencia.

Bajo esta lógica, el pensamiento sistémico y complejo son contribuyentes fundamentales para construir una paz estructurada, integral, sustentable y duradera. Su vinculación tanto en la construcción teórica como en la instalación práctica permite mantener mentes abiertas y creativas para integrar todo lo que puede ser potencial para constituir un mundo pacificador basado en la resolución de múltiples crisis.

\section{Referencias bibliográficas}

Checkland, P. (1993). Pensamiento de sistemas, práctica de sistemas. Departamento de sistemas Universidad de Lancaster.

GALTUNG, J. (1985). Sobre la paz. Barcelona: Fontamara.

GARcíA, R. (2006). Sistemas complejos. Conceptos, método y fundamentación epistemológica de la investigación interdisciplinar. Barcelona: Gedisa.

GHALI, B. (1992). Un programa de paz. Diplomacia Preventiva, establecimiento de la paz y mantenimiennto de la paz. Naciones Unidas.

GómeZ, D. (2017). Mujer, género y acuerdo de paz. Debates: Procesos de Paz en America Latina, 13-17.

Gonzales, A. (2016). ¿Qué es la paz territorial? Bogotá: Corporación Viva la Ciudadanía.

GonzÁLEZ, C. (2015). Los acuerdo de La Habana y la nueva política sobre los cultivos de uso ilícito. Instituto de Estudios para el Desarrollo y la Paz. Bogotá: Observatorio de Cultivos y Cultivadores Declarados Ilícitos -OCDI- Indepaz Proyecto Fase II Indepaz-OSF.

KANT, I. (1998). La paz perpetua. Editorial Tecnos, Sexta edición.

LederACH, J. (2007). Construyendo la Paz. Reconciliación Sostenible en Sociedades Divididas. Bogotá: Colección Red Gernika.

Medicina y Ética - Octubre-Diciembre 2019 - Vol. 30 - Núm. 4 
Magendzo, A., \& Pevéz, J. (2015). Educación en Derechos Humanos: Una propuesta para educar desde la perspectiva controversial. México: Comisión de Derechos Humanos del Distrito Federal. México.

MALDONADO, C. La complejidad es un problema, no una cosmovisión. UCM Revista de Investigación, 2009, 42-54.

MARTíneZ, V. (2008). Filosofía y Cultura para Hacer las Paces. Sevilla: Cátedra UNESCO, Filosofía para la paz, págs. 1-12.

MoRiello, S. (2016). Dinámica de los sistemas complejos. En Comunidad del Pensamiento Complejo. Disponible en: www.pensamientocomplejo.com.ar MoRín, E. (1990). Introducción al Pensamiento Complejo. Argentina: Gedisa. MoRín, E. (1994). La noción de sujeto. En: D. FRIED-SCHNITMAN. Nuevos paradigmas, Cultura y Subjetividad. Argentina: Paidós, págs. 67-86.

MoRín, E. (8 de agosto de 2014). Para un pensamiento del sur. Disponible en: http://ipcem.net/wp-content/uploads/2014/08/pensamiento_sur_edgar_morin.pdf MuÑoz, F. (2005). Una paz compleja, conflictiva e imperfecta. Disponible en: http:/ /www.ugr.es/ fmunoz/documentos/pazcompconfimperfdraf.pdf

Rettberg, A. (2002). Preparar el futuro: conflicto y post-conflicto en Colombia. Bogotá: Universidad de los Andes. Fundación Ideas para la Paz.

Rodríguez, L., \& AguiRRE, J. (2011). Teorías de la complejidad y Ciencias Sociales. Nuevas Estrategias Epistemológicas y Metodológicas. Nómadas. Revista científica de ciencias sociales y Jurídicas.

ROMERO, M. (2013). Factores de éxito en la resolución negociada de los conflictos armados. Centro de Pensamiento y Seguimiento a los Diálogos de Paz. Obtenido de http://pensamiento.unal.edu.co/fileadmin/recursos/focos/piensa-paz/policy_papers/documento_de_politicas_publicas_0.pdf

Roux, F. (2009). Discurso del Padre Roux en la Ceremonia de graduación de los estudiantes de la Universidad de los Andes. Bogotá: Universidad de los Andes.

SANDOVAL, E. (2015). Empoderamiento pacifista para otros mundos posibles. Revista de Paz y Conflictos, 75-95. SemanA. (2017). Viaje al Corazón de Tumaco. Revista Semana, 34.

TORTOSA, J. (2001). El largo camino de la violencia a la paz. Zaragoza: Universidad de Alinante, Cátedra Rafael Altamira.

UnAM, P. P. (09 de septiembre de 2016). Posgrado UnAM. Recuperado el 21 de mayo de 2017 de: http://psicologia.posgrado.unam.mx/wp-content/uploads/2016/ 05/258193358-Libro-Manual-de-Publicaciones-APA-Re.pdf

URIBE, D. (19 de junio de 2016). Dejemos de matarnos. El espíritu del acuerdo de paz. Bogotá. Recuperado en: https://www.youtube.com/watch?v=kVw_I9KItwc.

VALENCIA, L. (septiembre de 2016). Pastrana y Uribe, el 70,13 por ciento del total de víctimas. Semana.

VARGAS, G. (2017). Los retos de la paz territorial. Bogotá: Universidad de los Andes. Centro Interdisciplinario de Estudios sobre Desarrollo-DIDER. 